\title{
Erratum to: Female and male victims of violence in an urban emergency room-prevalence, sociodemographic characteristics, alcohol intake, and injury patterns
}

Nathalie Tatjana Burkert · Éva Rásky · Wolfgang Freidl · Franziska Großschädl ·
Johanna Muckenhuber · Renate Krassnig · Regina Gatternig · Herwig-Peter Hofer

Erratum to: Wien Klin Wochenschr (2013) 125:134-138. DOI 10.1007/00508-013-0329-z

Under the heading "Results" the second sentences should called: A total of $4.4 \%(\mathrm{~N}=143)$ of them stated that their injuries were caused by violent behavior.
Under the heading "Victims" the first sentences should called: In total, $90 \%$ of the victims of brawl were men.

The online version of the original article can be found under doi:http://dx.doi.org/10.1007/00508-013-0329-z

Univ.-Ass. Mag. N. T. Burkert ( $₫)$ · É. Rásky · W. Freidl ·

F. Großschädl · J. Muckenhuber

Institute of Social Medicine and Epidemiology,

Medical University Graz, Universitaetsstrasse 6/I,

8010 Graz, Austria

e-mail: nathalie.burkert@medunigraz.at

R. Krassnig · R. Gatternig · H.-P. Hofer

Trauma Surgery, University Hospital Graz, Graz, Austria 